\title{
Leaflet Disruption Due To Suture Abrasion
}

National Cancer Institute

\section{Source}

National Cancer Institute. Leaflet Disruption Due To Suture Abrasion. NCI Thesaurus.

Code C50908.

The disturbance of a cusp of a heart valve secondary to irritation by surgical sutures, which can result in valvular dysfunction. 